\title{
Elevation in D-Dimer Levels after the Surgical Treatment of Stage IA Extramammary Paget's Disease: A Risk of Deep Vein Thrombosis
}

\author{
Chika Ohata, Taichi Imamura, Hiroshi Saruta, TakekuniNakama \\ Department of Dermatology, Kurume University School of Medicine, Fukuoka 830-0011, Japan \\ ohata@med.kurume-u.ac.jp
}

\begin{abstract}
Background:D-dimer levels have been well studied among patients undergoing total hip replacement to measure the risk of deep vein thrombosis (DVT). However, no study has been conducted on the rate of DVT development in patients undergoing skin surgery.
\end{abstract}

Objective:To retrospectively review the postoperative frequency of DVT development and D-dimer levels in patients undergoing skin surgery.

Methods \& Materials:For analyzing patients with the same disease and the same affected anatomical region, we enrolled 12 patients with stage IA extramammary Paget's disease who were surgically treated in Kurume University Hospital between 2011 and 2014. We analyzed the postoperative rate of DVT development and changes in plasma D-dimer levels.

Results:No patient developed postoperative symptomatic DVT, but D-dimer levels were elevated in all patients postoperatively. The mean $\pm S D$ maximum $D$-dimer level was $4.1 \pm 2.7 \mu \mathrm{g} / \mathrm{ml}$ (normal, $\leq 1.0 \mu \mathrm{g} / \mathrm{ml}$ ). The mean \pm $S D$ postoperative day when the maximum D-dimer level was reached was $10.6 \pm 4.9$ days. Older patients $(\geq 75$ years) tended to have higher maximum $D$-dimer levels than younger patients ( $<75$ years).

Conclusion:Although elevated D-dimer levels may not be associated with DVT in this context, further studies may disclose a cutoff level for predicting DVT in patients undergoing skin surgery.

Keywords:Deep vein thrombosis, D-dimer, Extramammary Paget's disease, Older patients, Skin surgery

\section{INTRODUCTION}

Deep vein thrombosis (DVT) is a severe postoperative complication. It often occurs in patients undergoing total hip replacement, and studies have been conducted to elucidate the relationship between DVT and total hip replacement [1-3]. The levels of D-dimer, a highly sensitive marker of venous thromboembolism, have been studied among these patients to measure the risk of DVT [4-6]. Although patients undergoing lymphadenectomy for metastatic melanomas have been reported to develop DVT [7], the rate of the development of this condition among patients undergoing skin surgery has not been studied. In our daily practice, we have often experienced elevation in D-dimer levels in hospitalized patients undergoing surgery. This prompted us to study this phenomenon for better management. For this purpose, we focused our study on patients with the same disease and the same affected anatomical region. Therefore, in this study, we analyzed the postoperative rate of DVT development and changes in plasma D-dimer levels before and after the surgical treatment of stage IA extramammary Paget's disease (EMPD) involving perineal regions.

\section{METHODS}

We retrospectively selected all patients with stage IA EMPD involving perineal regions, who were surgically treated in Kurume University Hospital between 2011 and 2014. Although 15 patients with stage IA EMPD were treated during the study period, 3 were excluded because data on D-dimer levels were unavailable. We collected clinical data including age, sex, body mass index (BMI), a comorbidity requiring antithrombotic treatment, hospitalization duration, anesthesia type, operation 
time, skin graft or skin flap performance, postoperative thrombus, postoperative heparin use, and Ddimer levels from all enrolled patients. We divided the cohort into 2 groups in terms of each clinical parameter, and a t-test was performed to compare the maximum D-dimer levels between 2 groups. A level of $p<0.05$ was considered significant. Analysis was performed using JMP ${ }^{\circledR}$ Pro 11.0.0 (SAS Institute Inc., Cary, NC, U.S.A.). This study was approved by the Ethical Committee of Kurume University.

\section{RESULTS}

Clinical data are shown in Table 1, and the line chart of D-dimer levels for each patient is shown in Figure 1. Twelve patients were included ( 4 males and 8 females), with a mean age of $74.1 \pm 11.3$ years and a mean BMI of $23.8 \pm 3.8$. All patients wore compression stockings after the operation. No patient developed post-operative symptomatic DVT, but D-dimer levels were elevated in all patients post-operatively (Figure 1). Postoperative heparin was used in 2 patients for a couple of days to prevent DVT development based on the decision of the dermatologist in charge. The mean maximum D-dimer level was $4.1 \pm 2.7 \mu \mathrm{g} / \mathrm{ml}$ (normal, $\leq 1.0 \mu \mathrm{g} / \mathrm{ml}$ ). The mean post-operative day when the maximum D-dimer level was reached was $10.6 \pm 4.9$ days. Antithrombotic agents were used in 4 patients with a comorbidity of cerebrovascular disease, deep vein thrombus, or transient ischemic attack. The mean hospitalization duration was $31.3 \pm 14.0$ days. Lumbar anesthesia was used in 3 patients, and general anesthesia was used in the other 9. The mean operation time was $3 \pm 1 \mathrm{~h}$. A skin graft was used in 6 patients, and a skin flap was used in 1 patient. All patients spent 2 to 5 years without symptomatic thromboembolism after the surgery.

Figure 1.A line chart of D-dimer levels (BOP: before operation, OP: operation, POD: post-operative day).

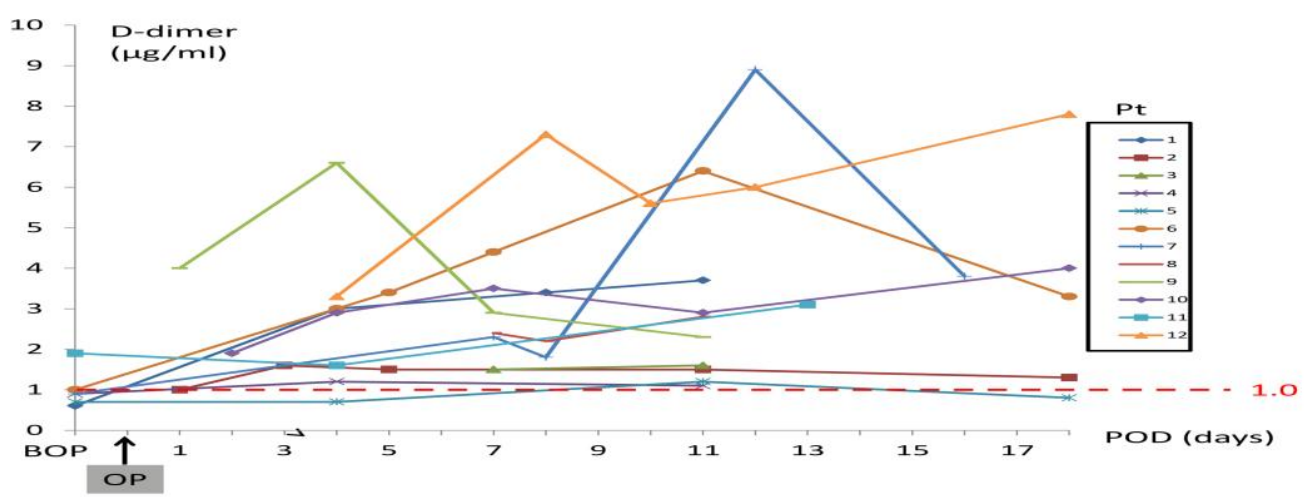

Table 1.Clinical data for patients with stage IA extramammary Paget's disease.M: male, F: female, BMI: body mass index, CVD: cerebrovascular disease, DVT: deep vein thrombus, TIA: transient ischemic attack, L: lumbar anesthesia, G:general anesthesia, POD:post-operative day, *:prostaglandin was given for spinal canal stenosis.

\begin{tabular}{|c|c|c|c|c|c|c|c|c|c|c|c|c|c|c|}
\hline $\mathbf{P t}$ & Age & Sex & BMI & $\begin{array}{l}\text { Comorbidity } \\
\text { requiring } \\
\text { antithrombot } \\
\text { ic agent }\end{array}$ & $\begin{array}{l}\text { Antith } \\
\text { rombo } \\
\text { tic } \\
\text { agent } \\
\text { for } \\
\text { comor } \\
\text { bidity }\end{array}$ & \begin{tabular}{|l|} 
Hospitali \\
zation \\
duration \\
(days)
\end{tabular} & Anesthesia & $\begin{array}{l}\text { Operation } \\
\text { time } \\
\text { (hours) }\end{array}$ & $\begin{array}{l}\text { Skin } \\
\text { graft }\end{array}$ & $\begin{array}{l}\text { Skin } \\
\text { flap }\end{array}$ & \begin{tabular}{|l} 
Post- \\
operati \\
ve \\
thromb \\
us
\end{tabular} & \begin{tabular}{|l} 
Post- \\
operati \\
ve \\
hepari \\
n
\end{tabular} & $\begin{array}{l}\text { Post- } \\
\text { ilopera } \\
\text { tive } \\
\text { max } \\
\text { D- } \\
\text { dimer } \\
\text { level } \\
(\mu \mathrm{g} / \mathrm{m} \\
\text { l) }\end{array}$ & \begin{tabular}{|l|} 
POD \\
of \\
max \\
D- \\
dime \\
r \\
(day \\
s) \\
\end{tabular} \\
\hline 1 & 51 & $\mathrm{~F}$ & 27.7 & - & - & 30 & $\mathrm{~L}$ & 1.0 & - & - & - & - & 3.7 & 11 \\
\hline 2 & 63 & $\mathrm{M}$ & 22.9 & - & - & 48 & $\mathrm{G}$ & 4.0 & + & - & - & - & 1.6 & 3 \\
\hline 3 & 64 & $\mathrm{~F}$ & 21.5 & - & - & 46 & $\mathrm{G}$ & 3.0 & - & + & - & - & 1.6 & 11 \\
\hline 4 & 67 & $\mathrm{~F}$ & 18.9 & - & - & 18 & $\mathrm{G}$ & 1.5 & - & - & - & - & 1.2 & 4 \\
\hline 5 & 73 & $\mathrm{~F}$ & 24.3 & CVD & + & 23 & $\mathrm{G}$ & 3.0 & - & - & - & - & 1.2 & 11 \\
\hline 6 & 73 & $\mathrm{~F}$ & 24.1 & unknown & + & 31 & $\mathrm{G}$ & 2.0 & - & - & - & - & 6.4 & 11 \\
\hline 7 & 79 & $\mathrm{~F}$ & 28.5 & DVT & + & 63 & $\mathrm{~L}$ & 2.5 & - & - & - & - & 8.9 & 12 \\
\hline 8 & 79 & $\mathrm{~F}$ & 18.7 & - & - & 21 & $\mathrm{G}$ & 4.0 & + & - & - & - & 2.8 & 11 \\
\hline 9 & 80 & $\mathrm{~F}$ & 29.4 & - & $-*$ & 26 & $G$ & 3.0 & + & - & - & + & 6.6 & 4 \\
\hline 10 & 83 & $\mathrm{M}$ & 27.9 & - & - & 24 & $\mathrm{G}$ & 4.0 & + & - & - & - & 4.0 & 18 \\
\hline 11 & 86 & $\mathrm{M}$ & 20.7 & TIA & + & 17 & $\mathrm{~L}$ & 3.5 & + & - & - & - & 3.1 & 13 \\
\hline 12 & \begin{tabular}{|l|}
91 \\
\end{tabular} & $\mathrm{M}$ & 21.5 & - & - & 28 & $\mathrm{G}$ & 4.5 & + & - & - & + & 7.8 & 18 \\
\hline
\end{tabular}


To elucidate the relationship between the D-dimer level and each clinical parameter, the postoperative maximum D-dimer level was analyzed using a t-test in terms of sex (male vs. female), age ( $<75$ years old vs. $\geq 75$ years), BMI ( $<25$ vs. $\geq 25$ ), hospitalization duration ( $<4$ weeks vs. $\geq 4$ weeks), anesthesia type (lumbar anesthesia vs. general anesthesia), operation time ( $\leq 3$ hours vs. $>3 \mathrm{~h}$ ), and skin graft/flap (used vs. not used) (Table 2). Although no significant difference was found in any parameter, older patients ( $\geq 75$ years) tended to have higher maximum D-dimer levels than younger patients ( $<75$ years).

Table 2.Comparison of maximum D-dimer levels between the 2 groups.M: male, F: female, BMI: body mass index, L: lumbaranesthesia, G: general anesthesia.

\begin{tabular}{|l|l|l|l|}
\hline & Group 1 & Group 2 & $\boldsymbol{p}$ \\
\hline Sex & M & F & 0.9664 \\
\hline Age & $<75 y .0$. & $\geq 75 y . o$. & 0.0565 \\
\hline BMI & $<25$ & $\geq 25$ & 0.1221 \\
\hline Hospitalized period & $<4 \mathrm{w}$ & $\geq 4 \mathrm{w}$ & 0.2543 \\
\hline Anesthesia & L & G & 0.4176 \\
\hline Operation time & $\leq 3 \mathrm{~h}$ & $>3 \mathrm{~h}$ & 0.8284 \\
\hline Skin graft or flap & used & not used & 0.8363 \\
\hline
\end{tabular}

\section{DISCUSSION}

Stage IA EMPD is defined as an in situ lesion without lymph node involvement or metastatic lesions $[8,9]$. The first line therapy for noninvasive lesions of EMPD is wide excision [10]; therefore, patients are usually hospitalized, and their physical activities often diminish. Immobilization is a known risk factor for DVT [11]; it particularly increases in hospitalized patients after surgical treatment, which seems to be one of the reasons for the high incidence of DVT in patients undergoing total hip replacement [1-3].

In our hospital, patients scheduled to be on bed rest for a couple of days are given compression stockings. Because we do not have criteria for postoperative heparin use, it was used according to the decision made by each attending physician; hence, the use of postoperative heparin was inconsistent in this study.

Previous studies have reported that DVT occurs mainly between days 4 and 6 post operation in patients undergoing total hip replacement and that the risk of DVT decreases over 2 weeks after surgery [1,12]. We measured D-dimer levels during this period in most patients and found that the maximum D-dimer level was obtained 11 days or more after the operation in 9 of the 12 patients. Thus, a relatively long period seems necessary for monitoring D-dimer levels. A previous study has revealed that a cutoff D-dimer level of $10.0 \mu \mathrm{g} / \mathrm{ml}$ (normal, $\leq 1.0 \mu \mathrm{g} / \mathrm{ml}$ ) on postoperative day 7 shows high specificity in making a diagnosis of DVT after total hip replacement.[5] The mean maximum Ddimer level of $4.1 \pm 2.7 \mu \mathrm{g} / \mathrm{ml}$ in the present study was relatively low compared to the previously reported cutoff level for DVT; this may be the reason for symptomatic DVT not developing.

The high sensitivity and low specificity of D-dimer levels in predicting DVT have been previously highlighted $[13,14]$. Previous studies have revealed that D-dimer levels increase in elderly individuals $[15,16]$. In addition, recent major surgery, trauma, infection, arrhythmias, cancer, pregnancy, and liver disease can elevate D-dimer levels [17-20]. Thus, the elevation in D-dimer levels in the present study may not be associated with DVT but rather with the operation itself and the high mean age because older patients tended to have higher D-dimer levels than younger patients.

This retrospective study has a limitation that patients were not examined by duplex ultrasonography or venography; hence, non-symptomatic DVT was not detected. However, most previous studies have dealt with only symptomatic DVT [1-3,14], reflecting the difficulty in studying non-symptomatic DVT. Another limitation is the inconsistent postoperative heparin use. Although most patients undergoing total hip replacement are postoperatively treated with antithrombotic agents such as enoxaparin according to the guidelines regardless of D-dimer levels [21-23], no standard guideline is available in patients undergoing skin surgery. It may be debatable whether heparin should have been used in non-symptomatic patients undergoing skin surgery with elevated D-dimer levels in this study. 


\section{CONCLUSION}

No patient developed symptomatic DVT; however non-symptomatic DVT could not be excluded. Although elevated D-dimer levels may not be associated with DVT in this context, further studies may disclose cutoff D-dimer levels for predicting DVT in patients undergoing skin surgery, as a previous orthopedic study revealed in patients undergoing total hip replacement[5].

\section{REFERENCES}

[1] Sikorski JM, Hampson WG, Staddon GE. The natural history and aetiology of deep vein thrombosis after total hip replacement. J Bone Joint Surg Br 63-B(2):171-177 (1981).

[2] Colwell CW Jr., Collis DK, Paulson R, McCutchen JW, Bigler GT, Lutz S, Hardwick ME. Comparison of enoxaparin and warfarin for the prevention of venous thromboembolic disease after total hip arthroplasty. Evaluation during hospitalization and three months after discharge. $\mathbf{J}$ Bone Joint Surg Am 81(7):932-940 (1999).

[3] Warwick D, Williams MH, Bannister GC. Death and thromboembolic disease after total hip replacement. A series of 1162 cases with no routine chemical prophylaxis. J Bone Joint Surg $\mathrm{Br}$ 77(1):6-10 (1995).

[4] Bounameaux H, Miron MJ, Blanchard J, de Moerloose P, Hoffmeyer P, Leyvraz PF. Measurement of plasma D-dimer is not useful in the prediction or diagnosis of postoperative deep vein thrombosis in patients undergoing total knee arthroplasty. Blood Coagul Fibrinolysis 9(8):749-752 (1998).

[5] Shiota N, Sato T, Nishida K, Matsuo M, Takahara Y, Mitani S, Murakami T, Inoue H. Changes in LPIA D-dimer levels after total hip or knee arthroplasty relevant to deep-vein thrombosis diagnosed by bilateral ascending venography. J OrthopSci 7(4):444-450 (2002).

[6] An TJ, Engstrom SM, Oelsner WK, Benvenuti MA, Polkowski GG, Schoenecker JG. Elevated dDimer Is Not Predictive of Symptomatic Deep Venous Thrombosis After Total Joint Arthroplasty. J Arthroplasty (2016).

[7] Sarnaik AA, Puleo CA, Zager JS, Sondak VK. Limiting the morbidity of inguinal lymphadenectomy for metastatic melanoma. Cancer Control 16(3):240-247 (2009).

[8] Yoshino K, Yamazaki N, Yamamoto A, Namikawa K, Abe M, Yoshida H. On the TNM Classification of Extramammary Paget's Disease (in Japanese). Jpn J Dermatol 116(9):1313-1318 (2006).

[9] Ohara K, Fujisawa Y, Yoshino K, Kiyohara Y, Kadono T, Murata Y, Uhara H, Hatta N, Uchi H, Matsushita S, Takenouchi T, Hayashi T, Yoshimura K, Fujimoto M. A proposal for a TNM staging system for extramammary Paget disease: Retrospective analysis of 301 patients with invasive primary tumors. J DermatolSci 83(3):234-239 (2016).

[10] Moller MG, Lugo-Baruqui JA, Milikowski C, Salgado CJ. Staged marginal contoured and central excision technique in the surgical management of perianal Paget's disease. Am J Surg 207(4):485-492 (2014).

[11] Rinde LB, Smabrekke B, Mathiesen EB, Lochen ML, Njolstad I, Hald EM, Wilsgaard T, Braekkan SK, Hansen JB. Ischemic Stroke and Risk of Venous Thromboembolism in the General Population: The Tromso Study. J Am Heart Assoc 5(11) (2016).

[12] Planes A, Vochelle N, Darmon JY, Fagola M, Bellaud M, Huet Y. Risk of deep-venous thrombosis after hospital discharge in patients having undergone total hip replacement: doubleblind randomised comparison of enoxaparin versus placebo. Lancet 348(9022):224-228 (1996).

[13] Stein PD, Hull RD, Patel KC, Olson RE, Ghali WA, Brant R, Biel RK, Bharadia V, Kalra NK. Ddimer for the exclusion of acute venous thrombosis and pulmonary embolism: a systematic review. Ann Intern Med 140(8):589-602 (2004).

[14] Haenssle HA, Ayad N, Buhl T, Rosenberger A, Thoms KM, Schon MP, Zutt M. Limited diagnostic value of Wells-score and D-dimer testing in hospitalized dermatologic patients with symptoms of deep vein thrombosis. Eur J Dermatol 23(6):830-836 (2013).

[15] Rumley A, Emberson JR, Wannamethee SG, Lennon L, Whincup PH, Lowe GD. Effects of older age on fibrin D-dimer, C-reactive protein, and other hemostatic and inflammatory variables in men aged 60-79 years. J ThrombHaemost 4(5):982-987 (2006). 
[16] Schutgens RE, Haas FJ, Biesma DH. Reduced efficacy of clinical probability score and D-dimer assay in elderly subjects suspected of having deep vein thrombosis. Br J Haematol 129(5):653657 (2005).

[17] Mahe I, Drouet L, Simoneau G, Minh-Muzeaux S, Caulin C, Bergmann JF. D-dimer can predict survival in patients with chronic atrial fibrillation. Blood Coagul Fibrinolysis 15(5):413-417 (2004).

[18] Querol-Ribelles JM, Tenias JM, Grau E, Querol-Borras JM, Climent JL, Gomez E, Martinez I. Plasma d-dimer levels correlate with outcomes in patients with community-acquired pneumonia. Chest 126(4):1087-1092 (2004).

[19] Ohlmann P, Faure A, Morel O, Petit H, Kabbaj H, Meyer N, Cheneau E, Jesel L, Epailly E, Desprez D, Grunebaum L, Schneider F, Roul G, Mazzucotteli JP, Eisenmann B, Bareiss P. Diagnostic and prognostic value of circulating D-Dimers in patients with acute aortic dissection. Crit Care Med 34(5):1358-1364 (2006).

[20] Knowlson L, Bacchu S, Paneesha S, McManus A, Randall K, Rose P. Elevated D-dimers are also a marker of underlying malignancy and increased mortality in the absence of venous thromboembolism. J ClinPathol 63(9):818-822 (2010).

[21] Geerts WH, Bergqvist D, Pineo GF, Heit JA, Samama CM, Lassen MR, Colwell CW. Prevention of venous thromboembolism: American College of Chest Physicians Evidence-Based Clinical Practice Guidelines (8th Edition). Chest 133(6 Suppl):381S-453S (2008).

[22] Mont MA, Jacobs JJ. AAOS clinical practice guideline: preventing venous thromboembolic disease in patients undergoing elective hip and knee arthroplasty. J Am AcadOrthopSurg 19(12):777-778 (2011).

[23] Bautista M, Llinas A, Bonilla G, Mieth K, Diaz M, Rodriguez F. Thromboprophylaxis after major orthopedic surgery: Improving compliance with clinical practice guidelines. Thromb Res 137:113-118 (2016).

Citation: Chika Ohata et al. Elevation in D-Dimer Levels after the Surgical Treatment of Stage IA Extramammary Paget's Disease: A Risk of Deep Vein Thrombosis. ARC Journal of Dermatology. 2017;2(1):11-15.

Copyright: (0) 2017 Chika Ohata, et al. This is an open-access article distributed under the terms of the Creative Commons Attribution License, which permits unrestricted use, distribution, and reproduction in any medium, provided the original author and source are credited. 